\title{
Aberrant expression of miR-4728 in patients with non-small cell lung cancer and its regulatory effects on tumor progression in tumor cells
}

\author{
YING HU ${ }^{1}$, XINFANG ZHANG ${ }^{2}$, CUIXUE GONG ${ }^{3}$ and JIANZHAO $\mathrm{LI}^{4}$ \\ ${ }^{1}$ Department of Blood Transfusion; ${ }^{2}$ Clinical Laboratory, Qilu Hospital Huantai Branch, Zibo, Shandong 256400; \\ ${ }^{3}$ Outpatient Dressing Room; ${ }^{4}$ Department of Pathology, Zibo Central Hospital, Zibo, Shandong 255000, P.R. China
}

Received April 3, 2020; Accepted July 21, 2020

DOI: $10.3892 /$ etm.2020.9141

\begin{abstract}
Non-small cell lung cancer (NSCLC) is a common malignant tumor with poor prognosis and an increasing number of cases. MicroRNA (miR)-4728 is related with the progression of various types of cancer, and is dysregulated in NSCLC, which indicates that miR-4728 may serve as a biomarker for NSCLC. The present study aimed to investigate the clinical significance of miR-4728 in NSCLC diagnosis and prognosis, and to explore the biological function of miR-4728 in NSCLC progression. Serum and tissue samples were collected from 122 patients with NSCLC. By conducting reverse transcription-quantitative PCR, the Cell Counting Kit-8 assay and Transwell assays, the expression of miR-4728 and its effect on NSCLC cell proliferation, migration and invasion were investigated. The diagnostic value of miR-4728 was evaluated by plotting a receiver operating characteristic curve, and Kaplan-Meier and Cox regression analyses were conducted to assess the prognostic value of miR-4728. miR-4728 was significantly downregulated in NSCLC serum and tissue samples compared with healthy controls, with a relatively high diagnostic accuracy and ability to predict poor overall survival time in patients with NSCLC. By conducting gain- and loss-of-function experiments, the results indicated that miR-4728 knockdown significantly promoted NSCLC cell proliferation, migration and invasion compared with the inhibitor negative control (NC) group. By contrast, miR-4728 overexpression displayed the opposite effect on NSCLC cell proliferation, migration and invasion. The present study indicated that miR-4728 was downregulated in NSCLC and may serve as a candidate diagnostic and prognostic biomarker. NSCLC cell proliferation, migration and invasion were
\end{abstract}

Correspondence to: Dr Jianzhao Li, Department of Pathology, Zibo Central Hospital, 54 Gongqingtuan Road, Zibo, Shandong 255000, P.R. China

E-mail: s88nch@163.com

Key words: non-small cell lung cancer, microRNA-4728, prognosis, diagnosis, tumor progression inhibited by miR-4728 overexpression compared with the mimic NC group, which suggested that miR-4728 may serve as a therapeutic target for NSCLC.

\section{Introduction}

Lung cancer poses §a serious threat to human health and has become a major concern worldwide (1). There are several subtypes of lung cancer, but it is classified into two main groups: Non-small-cell lung carcinoma (NSCLC) and small-cell lung carcinoma (SCLC) (2). NSCLC is the major subtype of epithelial lung malignancies, which is responsible for the increase in lung cancer-related deaths (3). Surgery is the most common treatment strategy for NSCLC, but it is only suitable for patients with stage I and II tumors; therefore, the incidence and mortality rate of patients with advanced stage remain poor. As a consequence, there is an urgent need to explore novel biomarkers for the diagnosis and prognosis of NSCLC.

Previous studies have reported a number of genes and signaling pathways that can serve as biomarkers during the progression of NSCLC, such as NF-kB, tumor suppressor candidate 3 and programmed death-ligand 1 (4-6). The role of microRNAs (miRNAs/miRs) in the prognosis and progression of various types of cancer has received increasing attention $(7,8)$. miRNAs are small non-coding RNAs that primarily mediate gene expression at the post-transcriptional level $(9,10)$. In the past decades, hundreds of miRNAs have been identified, among which a number of miRNAs have been determined as key molecules in numerous types of cancer. For example, miR-505 was downregulated in breast cancer and inhibited cell biological functions, which indicated the potential therapeutic target role of miR-505 (11). In gastric cancer, miR-574-5p promotes angiogenesis by targeting protein tyrosine phosphatase non-receptor type 3 (12). In NSCLC, several miRNAs have been reported to exert effects on cancer progression, especially dysregulated miRNAs. For instance, miR-374a serves as a prognostic marker for NSCLC, where its downregulation has been previously associated with poor patient survival (13). In another study, the downregulated miR-449b-3 expression in NSCLC has been reported to regulate epithelial-mesenchymal transition in NSCLC cells by targeting IL-6 (14). 
miR-4728 is downregulated in NSCLC, which indicates that it may serve as a biomarker for the disease $(15,16)$. The role of miR-4728 has been identified in a number of other types of cancer. miR-4728 is downregulated in papillary thyroid cancer and inhibits the progression of the disease by mediating the mitogen-activated protein kinase (MAPK) signaling pathway (17). In breast cancer, miR-4728 may serve as a marker of erb-b2 receptor tyrosine kinase 2 (HER-2), which is an important indicator of breast cancer (18). However, whether dysregulated miR-4728 expression also serves a pivotal role in the progression of NSCLC is not completely understood. The present study aimed to investigated the role of miR-4728 in the diagnosis and prognosis of NSCLC, and to explore the functional role of miR-4728 in tumor progression by assessing its effect on tumor cell proliferation, migration and invasion. The results of the present study may aid with understanding the pathogenesis of NSCLC and identifying a potential biomarker and therapeutic target for NSCLC.

\section{Materials and methods}

Patients and tissues. In the present study, 122 patients with NSCLC that underwent surgery at Qilu Hospital Huantai Branch were recruited between April 2011 and March 2013. During the same time period, 58 age- and gender-matched healthy volunteers (age range, 45-78 years; sex, 36 males and 22 females), who had no history of malignancies, were enrolled as healthy controls. All participants provided written informed consent. All patients had not received anti-tumor therapy prior to recruitment. Blood samples $(5 \mathrm{ml})$ were collected before surgery, cancerous tissues and matched adjacent non-cancerous tissues, which were collected at $\geq 3 \mathrm{~cm}$ from the edge of tumor, were collected during surgery. The tissues were histopathologically diagnosed by two experimenced histopathologists according to the diagnosis criteria by World Health Organization (19). Serum samples were isolated from the collected blood using centrifugation at $1,500 \mathrm{x}$ g at $4^{\circ} \mathrm{C}$ for $10 \mathrm{~min}$. All clinical samples were stored at $-80^{\circ} \mathrm{C}$ until further use. Table I presents the demographic and clinicopathologic data of patients. A 5-year follow-up survey was conducted after surgery, and the survival information of patients was obtained via telephone communication. The present study was approved by the Ethics Committee of Qilu Hospital Huantai Branch (approval no. HTh-200145).

Cell culture and transfection. NSCLC cell lines (A549, HCC827, NCI-H1299 and NCI-H1650) and a normal human lung epithelial cell line (BEAS-2B) were purchased from American Type Culture Collection. Cells were cultured in DMEM (Invitrogen; Thermo Fisher Scientific, Inc.) supplemented with $10 \%$ FBS (Invitrogen; Thermo Fisher Scientific, Inc.) at $37^{\circ} \mathrm{C}$ with $5 \% \mathrm{CO}_{2}$. Following overnight incubation in six-well plates, A549 and HCC827 cells (inoculum density of $2 \times 10^{6}$ cell/well) were cultured to $\sim 80 \%$ confluence before they were transfected with $50 \mathrm{nM}$ miR-4728 mimic, $100 \mathrm{nM}$ miR-4728 inhibitor, $50 \mathrm{nM}$ mimic negative control (NC) or $100 \mathrm{nM}$ inhibitor NC using Lipofectamine ${ }^{\circledR} 2000$ (Invitrogen; Thermo Fisher Scientific, Inc.), according to the manufacturer's protocol. The subsequent cell experiments were peformed $48 \mathrm{~h}$ post-transfection. All mimics and inhibitors were synthesized by Shanghai GenePharma Co., Ltd. and the sequences were as follows: miR-4728 mimic, 5'-CAUGCUGACCUCCCUCCU GCCCCAG-3'; miR-4728 inhibitor, 5'-CUGGGGCAGGAG GGAGGUCAGCAUG-3'; mimic NC, 5'-UUCUCCGAACGU GUCACGU-3'; inhibitor NC, 5'-CAGUACUUUUGUGUA GUACAA-3'.

$R N A$ extraction and reverse transcription-quantitative $P C R$ $(R T-q P C R)$. Total RNA was extracted from serum samples, tissues and cell lines using TRIzol ${ }^{\circledR}$ (Invitrogen; Thermo Fisher Scientific, Inc.) according to the manufacturer's instructions. Total RNA was reverse transcribed into cDNA using a High Capacity cDNA Reverse Transcription kit (Applied Biosystems; Thermo Fisher Scientific, Inc.) with the following conditions: $42^{\circ} \mathrm{C}$ for $30 \mathrm{~min}$ and $85^{\circ} \mathrm{C}$ for $5 \mathrm{sec}$. Subsequently, qPCR was performed using the SYBR-green I Master mix kit (Invitrogen; Thermo Fisher Scientific, Inc.) in a 7300 Real-Time PCR system (Applied Biosystems; Thermo Fisher Scientific, Inc.). The thermocycling conditions were as follows: Initial denaturation at $95^{\circ} \mathrm{C}$ for $10 \mathrm{~min}$ followed by 40 cycles of denaturation at $95^{\circ} \mathrm{C}$ for $30 \mathrm{sec}$, annealing at $60^{\circ} \mathrm{C}$ for $20 \mathrm{sec}$ and elongation at $72^{\circ} \mathrm{C}$ for $30 \mathrm{sec}$, before final extension at $72^{\circ} \mathrm{C}$ for $10 \mathrm{~min}$. miRNA expression levels were quantified using the $2^{-\Delta \Delta \mathrm{Cq}}$ method (20) and normalized to the internal reference gene U6. The primer sequences used were as follows: miR-4728 forward, 5'-GCCGAGCATGCTGACCTCCC-3' and reverse, 5'-CTCAACTGGTGTCGTGGA-3'; U6 forward, 5'-CTCGCTTCGGCAGCACA-3' and reverse, 5'-AACGCT TCACGAATTTGCGT-3'.

Cell Counting Kit-8 (CCK-8) assay. Cell proliferation was assessed using a CCK-8 assay (Dojindo Molecular Technologies, Inc.) according to the manufacturer's protocol. In brief, transfected cells $\left(5 \times 10^{3}\right.$ cells/well) were seeded into 96 -well plates. Following incubation for $0,24,48$ or $72 \mathrm{~h}$, cell proliferation was assessed by incubating cells with $10 \mu \mathrm{l}$ CCK- 8 reagent for $4 \mathrm{~h}$ at $37^{\circ} \mathrm{C}$ with $5 \% \mathrm{CO}_{2}$. The absorbance of each well was measured at a wavelength of $450 \mathrm{~nm}$ using a microplate reader.

Transwell assay. A Transwell assay (Corning, Inc.) was conducted using $8-\mu \mathrm{m}$ pore membranes to assess NSCLC cell migration and invasion. To assess cell migration, transfected cells $\left(2 \times 10^{5}\right)$ in serum-free DMEM (Invitrogen; Thermo Fisher Scientific, Inc.) were seeded into the upper chamber. DMEM supplemented with 5\% FBS (Invitrogen; Thermo Fisher Scientific, Inc.) was added to the lower chamber as a chemoattractant. Following incubation for $24 \mathrm{~h}$, migratory cells were stained with $0.1 \%$ crystal violet at room temperature for $10 \mathrm{~min}$ and quantified using a light microscope (magnification, $x 200)$. For cell invasion, the upper chambers were precoated with Matrigel (BD Biosciences) at $37^{\circ} \mathrm{C}$ for $6 \mathrm{~h}$ prior to Transwell assay.

Western blotting. Total protein was extracted from A549 cells using RIPA buffer (Beyotime Institute of Biotechnology) and quantified using a BCA protein assay kit (Beyotime Institute of Biotechnology). Proteins (30 $\mu \mathrm{g} /$ lane) were separated via $10 \%$ SDS-PAGE and transferred to PVDF membranes (EMD Millipore), which were blocked with $5 \%$ non-fat milk at room temperature for $2 \mathrm{~h}$. Subsequently, 
Table I. Association between miR-4728 expression levels and the clinicopathologic parameters of patients with non-small cell lung cancer.

\begin{tabular}{|c|c|c|c|c|c|c|c|}
\hline \multirow[b]{2}{*}{ Parameter } & \multirow[b]{2}{*}{ Total $(\mathrm{n}=122)$} & \multicolumn{2}{|c|}{ Serum miR-4728 } & \multirow[b]{2}{*}{ P-value } & \multicolumn{2}{|c|}{ Tissue miR-4728 } & \multirow[b]{2}{*}{ P-value } \\
\hline & & Low $(\mathrm{n}=65)$ & High (n-57) & & Low $(n=67)$ & High $(n=55)$ & \\
\hline Age & & & & 0.796 & & & 0.596 \\
\hline$<60$ & 52 & 27 & 25 & & 30 & 22 & \\
\hline$\geq 60$ & 70 & 38 & 32 & & 37 & 33 & \\
\hline Gender & & & & 0.257 & & & 0.154 \\
\hline Male & 75 & 43 & 32 & & 45 & 30 & \\
\hline Female & 47 & 22 & 25 & & 22 & 25 & \\
\hline Tumour size $(\mathrm{cm})$ & & & & 0.043 & & & 0.042 \\
\hline$<4$ & 63 & 28 & 35 & & 29 & 34 & \\
\hline$\geq 4$ & 59 & 37 & 22 & & 38 & 21 & \\
\hline Smoking history & & & & 0.596 & & & 0.541 \\
\hline No & 48 & 27 & 21 & & 28 & 20 & \\
\hline Yes & 74 & 38 & 36 & & 39 & 35 & \\
\hline Differentiation & & & & 0.519 & & & 0.743 \\
\hline Well + moderate & 69 & 35 & 34 & & 37 & 32 & \\
\hline Poor & 53 & 30 & 23 & & 30 & 23 & \\
\hline Lymph node metastasis & & & & 0.002 & & & 0.002 \\
\hline Negative & 72 & 30 & 42 & & 31 & 41 & \\
\hline Positive & 50 & 35 & 15 & & 36 & 14 & \\
\hline TNM stage & & & & 0.001 & & & 0.001 \\
\hline I-II & 71 & 29 & 42 & & 30 & 41 & \\
\hline III-IV & 52 & 36 & 15 & & 37 & 14 & \\
\hline
\end{tabular}

miR, microRNA.

the membranes were incubated at $4^{\circ} \mathrm{C}$ overnight with the following primary antibodies: Anti-phosphorylated (p)-ERK1/2 (1:1,000; cat. no. ab214362; Abcam), anti-ERK1/2 (1:10,000; cat. no. ab184699; Abcam), anti-Bcl-2 (1:1,000; cat. no. ab32124; Abcam), anti-Bax (1:1,000; cat. no. ab32503; Abcam), anti- $\beta$-actin (1:500; cat. no. ab8229; Abcam). Following primary incubation, the membranes were incubated with a horseradish peroxidase-conjugated secondary antibody (1:5,000; cat. no. 715-035-151; Jackson ImmunoResearch Laboratories, Inc.) at room temperature for $1 \mathrm{~h}$. Protein bands were visualized using an enhanced chemiluminescent substrate (Bio-Rad Laboratories, Inc.) and ImageLab version 4.1 software (Bio-Rad Laboratries, Inc.). $\beta$-actin was used as the loading control.

Statistical analysis. Data are presented as the mean \pm SD of triplicate experiments. Differences between groups were analyzed using the $\chi^{2}$ test, t-test or one-way ANOVA followed by Tukey's post hoc test. The paired Student's t-test was used to analyze miR-4728 expression between tumor and normal tissues, whilst the unpaired Student's t-test was used to compare the differences in serum miR-4728 expression between patients with NSCLC and healthy individuals. Statistical analyses were conducted using SPSS (version 20.0;
IBM Corp.) and GraphPad Prism (version 5.0; GraphPad Software, Inc.) software. A receiver operating characteristic (ROC) curve was plotted to evalute the diagnsotic value of miR-4728. The Kaplan-Meier method and log-rank test were used to plot survival curves and compare the different distributions between the curves, and Cox regression analysis was used to assess the prognostic ability of miR-4728. $\mathrm{P}<0.05$ was considered to indicate a statistically significant difference.

\section{Results}

miR-4728 is downregulated in patients with NSCLC and NSCLC cells. The present study evaluated the relative expression of miR-4728 in NSCLC serum samples, tissues and cell lines. Compared with healthy controls, patients with NSCLC displayed significantly decreased miR-4728 serum expression levels $(\mathrm{P}<0.01$; Fig. 1A). The expression of miR-4728 in tumor tissues was also significantly lower compared with adjacent noncancerous tissues ( $\mathrm{P}<0.01$; Fig. 1B). In addition, the expression of miR-4728 was decreased in the four NSCLC cell lines compared with normal BEAS-2B cells (all $\mathrm{P}<0.01$; Fig. 1C).

miR-4728 is associated with the TNM stage of patients. The clinicopathological features of patients are presented in 

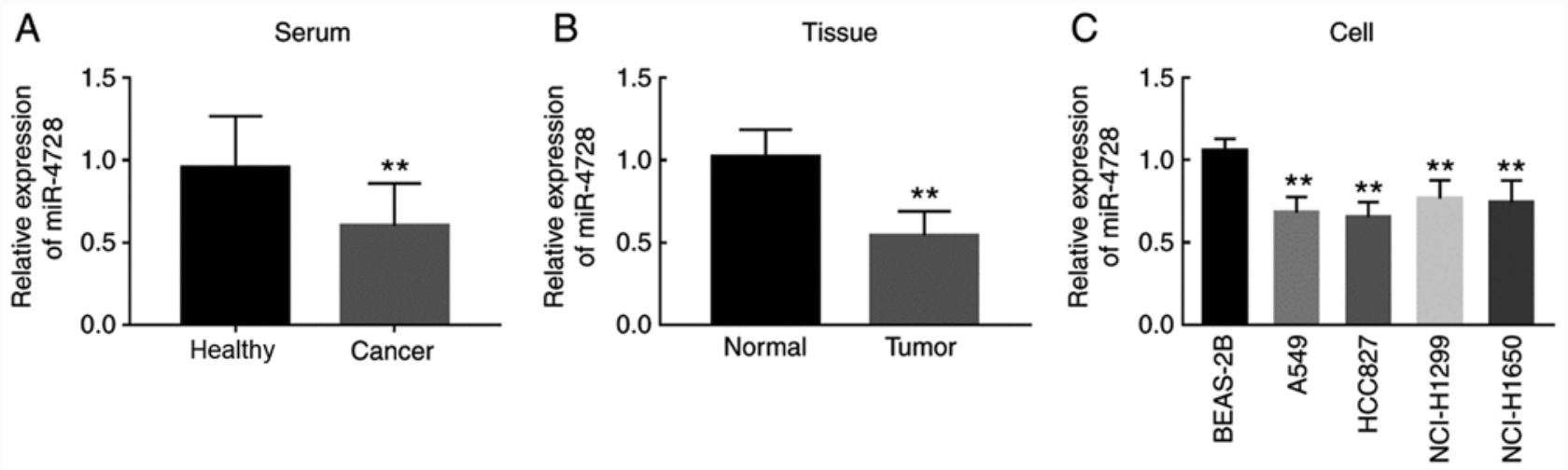

Figure 1. Relative expression of miR-4728 in patients with NSCLC and NSCLC cell lines. (A) miR-4728 was significantly downregulated in NSCLC serum samples. ${ }^{* * *} \mathrm{P}<0.01$ vs. Healthy. (B) miR-4728 was significantly downregulated in NSCLC tissue samples compared with that in healthy controls. ${ }^{* *} \mathrm{P}<0.01 \mathrm{vs}$. Normal. (C) miR-4728 was significantly downregulated in NSCLC cell lines (A549, HCC827, NCI-H1299 and NCI-H1650) compared with BEAS-2B cells. ${ }^{* *} \mathrm{P}<0.01$ vs. BEAS-2B. miR, microRNA; NSCLC, non-small cell lung cancer.

Table I. The TNM stages of the pateints were determined based on the criteria set by the American Joint Committee on Cancer classification (21). According to the median expression values (serum expression, 0.642; tissue expression, 0.547), patients were divided into high and low miR-4728 expression level groups. The results indicated that the expression of miR-4728 in serum and tissue samples was significantly associated with tumor size, lymph node metastasis and TNM stage (all $\mathrm{P}<0.05$ ) in patients with NSCLC, but there was no significant association between miR-4728 expression and other clinicopathological features (all $\mathrm{P}>0.05$; Table I).

Diagnostic performance of serum miR-4728 in patients with NSCLC. By assessing the serum levels of miR-4728, the ROC curve suggested that the area under the curve was 0.813 , indicating that miR- 4728 was a relatively accurate diagnostic marker in patients with NSCLC (Fig. 2). The diagnosis sensitivity and specificity of miR-4728 were 77.9 and $75.9 \%$, respectively, with a cutoff value of 0.788 .

miR-4728 is an independent prognostic factor in patients with NSCLC. Kaplan-Meier curves were plotted based on survival information obtained by conducting a 5-year follow-up survey. Patients with low tissue miR-4728 expression displayed a worse survival time compared with patients with high tissue miR-4728 expression ( $\mathrm{P}=0.013$; Fig. 3). The prognosis value of miR-4728 was evaluated by performing Cox regression analysis. The results indicated that the independent prognostic value of miR-4728 expression had a hazard ratio value of 2.030 (95\% confidence interval $=1.012-4.072 ; \mathrm{P}=0.042$; Table II).

Regulatory effect of miR-4728 on NSCLC cell proliferation. miR-4728 expression was overexpressed and knocked down by transfecting A549 and HCC827 cells with miR-4728 mimic and miR-4728 inhibitor, respectively ( $\mathrm{P}<0.001$; Fig. 4A and B). The effect of miR-4728 overexpression or knockdown on A549 and HCC 827 cell proliferation was assessed by performing the CCK-8 assay. Compared with that in the corresponding NC groups, cell proliferation was significantly inhibited by miR-4728 overexpression, but significantly enhanced by miR-4728 knockdown, respectively $(\mathrm{P}<0.05$; Fig. $4 \mathrm{C}$ and $\mathrm{D})$. To further investigate the regulatory effect of miR-4728 on

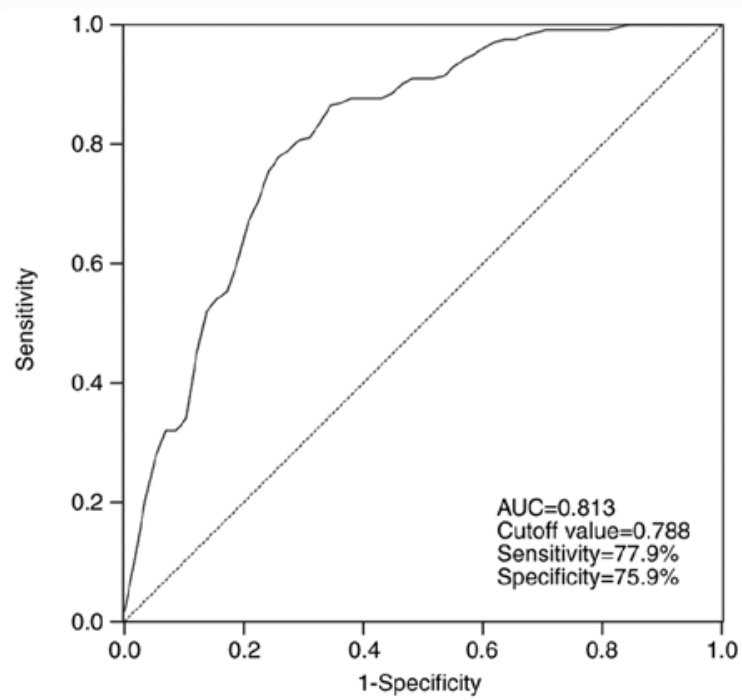

Figure 2. Receiver operating characteristic curve based on serum miR-4728 expression. AUC, area under the curve.

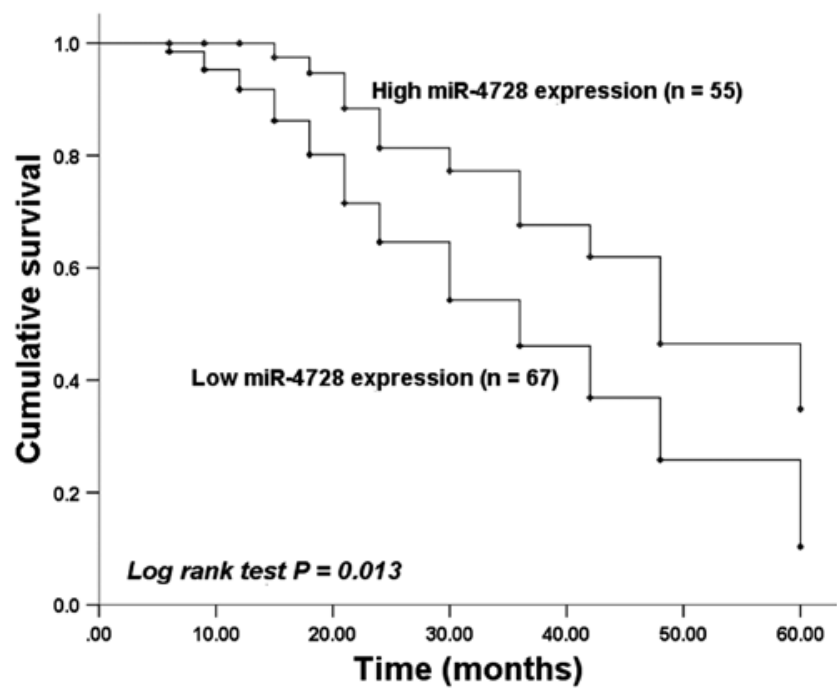

Figure 3. Kaplan-Meier curve of miR-4728 expression in patients with non-small cell lung cancer. Patients with low miR-4728 expression had a worse overall survival rate compared with patients with high miR-4728 expression. miR, microRNA. 
Table II. Cox regression analysis in patients with non-small cell lung cancer.

\begin{tabular}{lccr}
\hline Variable & Hazard ratio & 95\% confidence interval & P-value \\
\hline MicroRNA-4728 & 2.030 & $1.012-4.072$ & 0.042 \\
Age & 1.249 & $0.654-2.384$ & 0.500 \\
Gender & 1.224 & $0.665-2.252$ & 0.515 \\
Tumor size & 1.504 & $0.822-2.752$ & 0.186 \\
Smoking history & 1.485 & $0.728-2.699$ & 0.248 \\
Differentiation & 1.656 & $0.893-3.072$ & 0.109 \\
Lymph node metastasis & 1.523 & $0.807-2.873$ & 0.194 \\
TNM stage & 1.668 & $0.907-3.066$ & 0.059
\end{tabular}

A
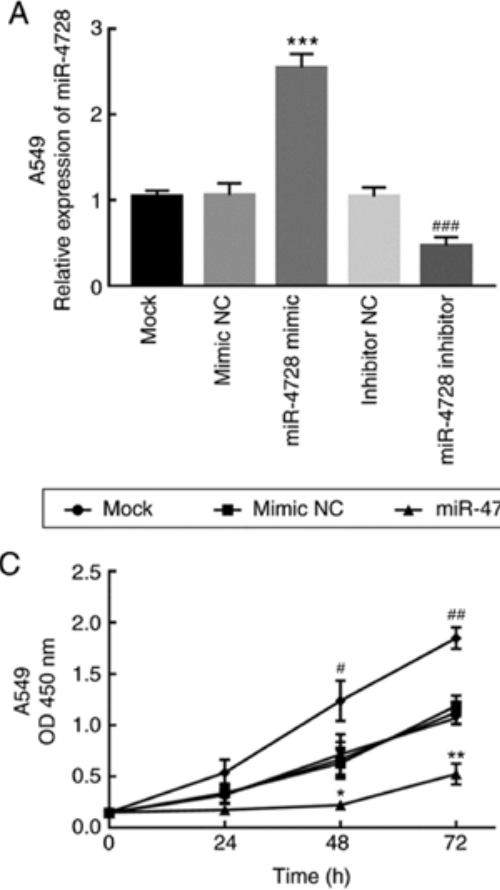

E

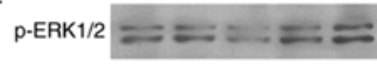

ERK $1 / 2= \pm \equiv=$

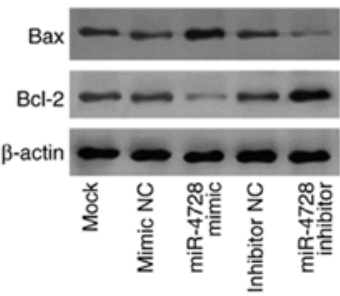

F $\quad-$ Mock $=$ Mimic NC $=$ Inhibitor NC

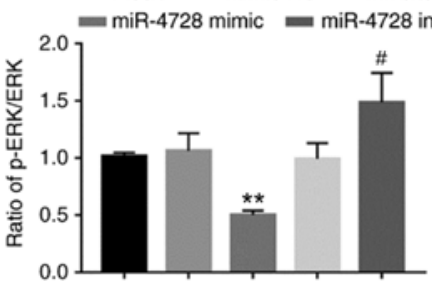

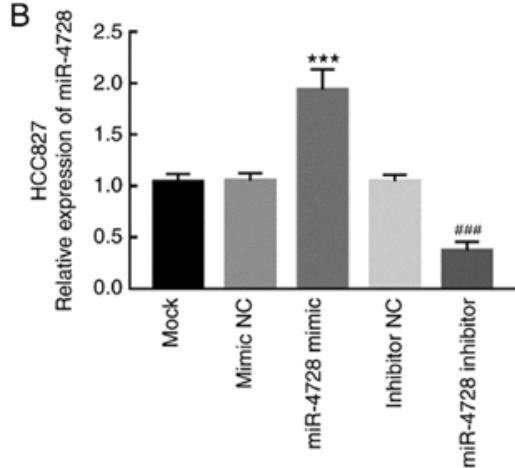

$\rightarrow$ Inhibitor NC $\rightarrow$ miR-4728 inhibitor

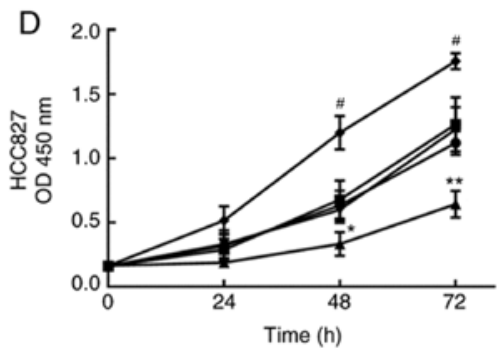

Mock $=$ Mimic NC $=$ Inhibitor NC

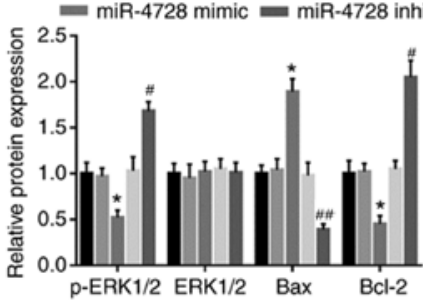

Figure 4. Effect of miR-4728 expression on non-small cell lung cancer cell proliferation. Transfection efficiency of miR-4728 mimic and miR-4728 inhibitor in (A) A549 and (B) HCC827 cells. Effect of miR-4728 on (C) A549 and (D) HCC827 cell proliferation. (E) Effect of miR-4728 on the expression of ERK signaling pathway- and cell apoptosis-associated proteins. (F) Ratio of p-ERK/ERK in A549 cells. ${ }^{*} \mathrm{P}<0.05,{ }^{* *} \mathrm{P}<0.01$ and ${ }^{* * * *} \mathrm{P}<0.001$ vs. mimic NC; ${ }^{\#} \mathrm{P}<0.05$, ${ }^{\# \#} \mathrm{P}<0.01,{ }^{\# \#} \mathrm{P}<0.001$ vs. inhibitor NC. miR, microRNA; $p$, phosphorylated; NC, negative control; OD, optical density. 

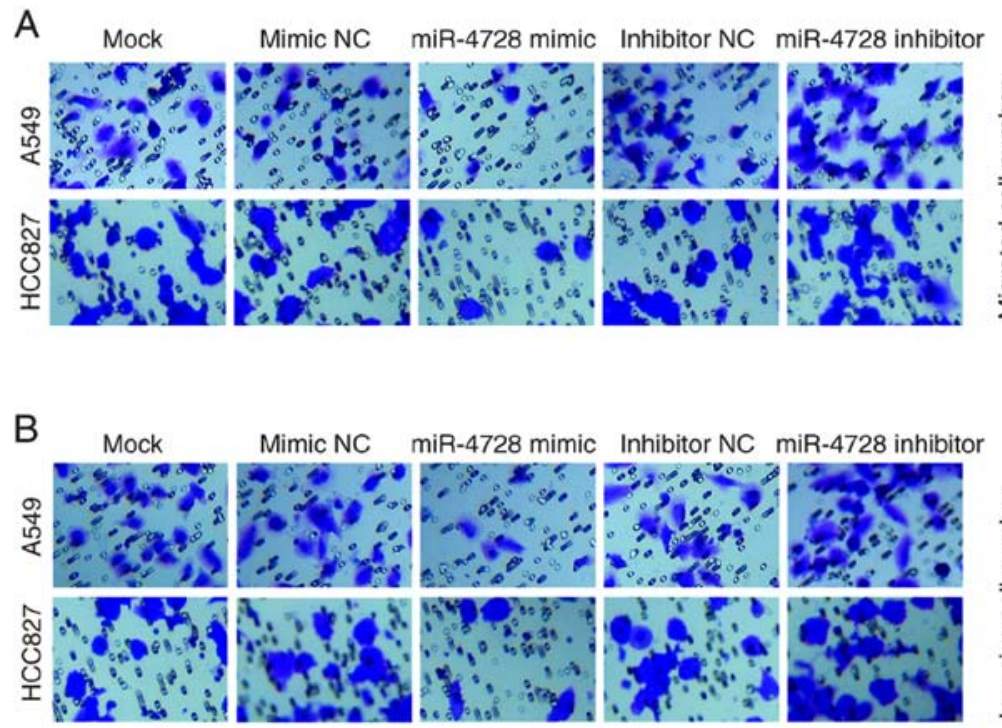
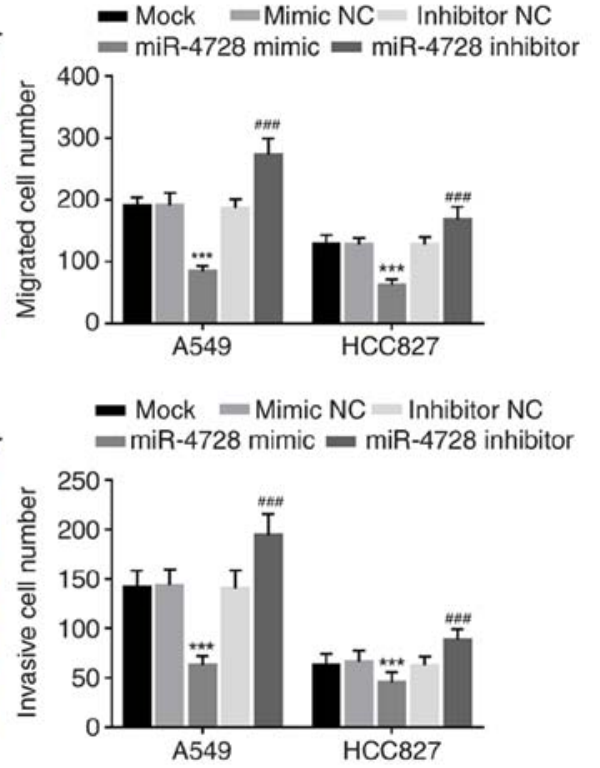

Figure 5. Effect of miR-4728 on A549 and HCC 827 cell migration and invasion. Effect of miR-4728 on cell (A) migration and (B) invasion. Magnification of $\mathrm{x} 200 .{ }^{* * *} \mathrm{P}<0.001$ vs. mimic NC; ${ }^{\# \# \#} \mathrm{P}<0.001$ vs. inhibitor NC. miR, microRNA; NC, negative control.

NSCLC cell viability, the activity of the ERK signaling pathway and apoptosis-related protein expression levels were analyzed in A549 cells. The results indicated that, compared with the corresponding NC groups, miR-4728 overexpression inhibited the ERK signaling pathway, whereas miR-4728 knockdown promoted the ERK signaling pathway, as indicated by alterations to the p-ERK/ERK ratio $(\mathrm{P}<0.05$; Fig. $4 \mathrm{E}$ and $\mathrm{F})$. In addition, miR-4728 overexpression significantly increased Bax expression and decreased Bcl-2 expression compared with the mimic $\mathrm{NC}$ group (all $\mathrm{P}<0.05$; Fig. $4 \mathrm{E}$ ). By contrast, miR-4728 knockdown displayed the opposite effects on Bax and $\mathrm{Bcl}-2$ expression levels compared with the inhibitor NC group (all $\mathrm{P}<0.05$; Fig. 4E). The results demonstrated that miR-4728 might suppress NSCLC cell viability.

miR-4728 inhibits NSCLC cell migration and invasion. The effect of miR-4728 on A549 and HCC827 cell migration and invasion was analyzed by performing Transwell assays. miR-4728 overexpression significantly inhibited A549 and HCC827 cell migration compared with the mimic NC group, whereas miR-4728 knockdown significantly promoted A549 and HCC 827 cell migration compared with the inhibitor NC group (all $\mathrm{P}<0.001$; Fig. 5A). Similarly, the number of invasive cells was significantly decreased by miR-4728 overexpression compared with the mimic NC group, but significantly increased by miR-4728 knockdown compared with the inhibitor NC group ( $\mathrm{P}<0.001$; Fig. 5B).

\section{Discussion}

NSCLC is one of the most common malignant tumors that threatens human health, with an increasing number of cases and rising death rate (22). Although therapeutic strategies have been developed in the past few decades, the prognosis of NSCLC remains poor (23-25). Previously, numerous biomarkers have been demonstrated to serve roles in the prognosis and progression of NSCLC, including a variety of miRNAs, especially dysregulated miRNAs. For example, miR-593 was reduced in NSCLC, and inhibited NSCLC cell migration and invasion by targeting snail family transcriptional repressor 2-related signaling pathways (26). miR-449b could inhibit NSCLC cell proliferation and invasion by targeting leucine rich repeat containing G protein-coupled receptor 4 (27). Moreover, miR-650 was upregulated and associated with an unfavorable survival rate in lung cancer, which enhanced cell proliferation and invasion (28). Additionally, exploring miRNAs that serve roles in NSCLC is important for the identification of novel therapeutic targets for NSCLC.

miRNAs that are associated with the progression and metastasis of cancer serve as biomarkers in multiple types of cancer and tumors. miR-216b is downregulated in cervical cancer and correlated with poor prognosis, which inhibits cell proliferation, migration and invasion by targeting forkhead box M1 (29). miR-153 overexpression is correlated with poor prognosis and key clinical features in patients with prostate cancer, which indicated that miR-153 may serve as a biomarker for prostate cancer (30). miR-4728 has been described as a suppressor of breast cancer by inhibiting MAPK signaling pathway, and the expression of miR-4728 was associated with the status of HER-2 $(18,31)$. miR-4728 also regulates estrogen receptor 1 via a non-canonical internal seed interaction (32). In papillary thyroid cancer, miR-4728 was identified as a therapeutic target for its dysregulation and function during the prognosis and progression of papillary thyroid cancer (17).

In the present study, miR-4728 was downregulated in NSCLC serum samples and tissues compared with healthy controls. miR-4728 expression was also significantly associated with tumor size, lymph node metastasis and TNM stage in patients with NSCLC. Similarly, in NSCLC cell lines, miR-4728 was downregulated compared with BEAS-2B cells. Moreover, miR-4728 knockdown promoted NSCLC cell proliferation, migration and invasion compared with the mimic NC group. The ROC analysis results indicated that serum 
miR-4728 expression had relatively high diagnostic accuracy in patients with NSCLC, and the survival analysis indicated that decreased miR-4728 expression in patients with NSCLC predicted poor prognosis and might serve as an independent prognostic biomarker. The results indicated the considerable clinical value of miR-4728 in NSCLC and the vital role during the progression of NSCLC, which was consistent with previous studies $(15,16)$.

The present results indicated the role of miR-4728 in the progression of NSCLC, and provided a potential therapeutic target for NSCLC. Although the results indicated that miR-4728 inhibited NSCLC cell proliferation and regulated cell apoptosis-related proteins, the effect of miR-4728 on cell apoptosis was not examined in the present study, which may be a limitation. In addition, the present study overlooked the mechanism underlying the functional role miR-4728, which may aid with understanding the function of miR-4728. Therefore, further studies that comprehensively analyze the biological function of miR-4728 in NSCLC progression and focus on the underlying mechanism should be performed. Furthermore, the majority of the experiments conducted in the present study were performed in vitro, therefore, in vivo experiments need to be conducted to verify the results.

In conclusion, the present study indicated that patients with NSCLC displayed reduced expression levels of miR-4728 in serum and tissue samples compared with healthy controls. Therefore, the results suggested that dysregulated miR-4728 may serve as a candidate diagnostic and prognostic biomarker of NSCLC. Compared with the mimic NC group, miR-4728 overexpression inhibited NSCLC cell proliferation, migration and invasion, which indicated that miR-4728 may be involved in tumor pathogenesis. Therefore, elevating miR-4728 expression levels may serve as a therapeutic strategy for NSCLC.

\section{Acknowledgements}

The authors would like to express gratitude to the two experienced histopathologists Dr Jiansheng Rong and Dr Baohua Zhang (Department of Pathology, Zibo Central Hospital, Zibo, China), who contributed to the histopathologic diagnosis of the tissue samples.

\section{Funding}

No funding was recieved.

\section{Availability of data and materials}

The datasets used and/or analyzed during the present study are available from the corresponding author on reasonable request.

\section{Authors' contributions}

YH and JL designed this study and analyzed the expression of miR-4728 in serum and tissue samples, as well as the clinical data. XZ and CG performed the cell experiments and analyzed the corresponding data. YH wrote the manuscript. All authors read and approved the final manuscript.

\section{Ethics approval and consent to participate}

The present study was approved by the Ethics Committee of Qilu Hospital Huantai Branch (approval no. HTh-200145). Written informed consent was obtained from each participant.

\section{Patient consent for publication}

Not applicable.

\section{Competing interests}

The authors declare that they have no competing interests.

\section{References}

1. Nasim F, Sabath BF and Eapen GA: Lung cancer. Med Clin North Am 103: 463-473, 2019.

2. Mao Y, Yang D, He J and Krasna MJ: Epidemiology of lung cancer. Surg Oncol Clin N Am 25: 439-445, 2016.

3. Herbst RS, Heymach JV and Lippman SM: Lung cancer. N Engl J Med 359: 1367-1380, 2008.

4. Dimitrakopoulos FD, Antonacopoulou AG, Kottorou AE, Maroussi S, Panagopoulos N, Koukourikou I, Scopa C, Kalofonou M, Koutras A, Makatsoris T, et al: NF-kB2 genetic variations are significantly associated with non-small cell lung cancer risk and overall survival. Sci Rep 8: 5259, 2018.

5. Feng S, Zhai J, Lu D, Lin J, Dong X, Liu X, Wu H, Roden AC, Brandi G, Tavolari S, et al: TUSC3 accelerates cancer growth and induces epithelial-mesenchymal transition by upregulating claudin-1 in non-small-cell lung cancer cells. Exp Cell Res 373: 44-56, 2018.

6. Sahin S, Batur S, Aydin O, Ozturk T, Turna A and Oz B: Programmed death-ligand-1 expression in non-small cell lung cancer and prognosis. Balkan Med J 36: 184-189, 2019.

7. Hayes J, Peruzzi PP and Lawler S: MicroRNAs in cancer: Biomarkers, functions and therapy. Trends Mol Med 20: 460-469, 2014.

8. Wu KL, Tsai YM, Lien CT, Kuo PL and Hung AJ: The roles of MicroRNA in lung cancer. Int J Mol Sci 20: 1611, 2019.

9. Liu S, Yang Y, Jiang S, Tang N, Tian J, Ponnusamy M, Tariq MA, Lian $\mathrm{Z}$, Xin $\mathrm{H}$ and $\mathrm{Yu} \mathrm{T}$ : Understanding the role of non-coding RNA (ncRNA) in stent restenosis. Atherosclerosis 272: 153-161, 2018.

10. Palomer X, Pizarro-Delgado J and Vazquez-Carrera M: Emerging actors in diabetic cardiomyopathy: Heartbreaker biomarkers or therapeutic targets? Trends Pharmacol Sci 39: 452-467, 2018.

11. Wang J, Liu H and Li M: Downregulation of miR-505 promotes cell proliferation, migration and invasion, and predicts poor prognosis in breast cancer. Oncol Lett 18: 247-254, 2019.

12. Zhang S, Zhang R, Xu R, Shang J, He H and Yang Q: MicroRNA-574-5p in gastric cancer cells promotes angiogenesis by targeting protein tyrosine phosphatase non-receptor type 3 (PTPN3). Gene 733: 144383, 2020.

13. Vosa U, Vooder T, Kolde R, Fischer K, Valk K, Tonisson N, Roosipuu R, Vilo J, Metspalu A and Annilo T: Identification of miR-374a as a prognostic marker for survival in patients with early-stage nonsmall cell lung cancer. Genes Chromosomes Cancer 50: 812-822, 2011.

14. Cai K, Li HX, Li PP, Guo ZJ and Yang Y: MicroRNA-449b-3p inhibits epithelial-mesenchymal transition by targeting IL- 6 and through the JAK2/STAT3 signaling pathway in non-small cell lung cancer. Exp Ther Med 19: 2527-2534, 2020.

15. Cai T, Long J, Wang H, Liu W and Zhang Y: Identification and characterization of miR-96, a potential biomarker of NSCLC, through bioinformatic analysis. Oncol Rep 38: 1213-1223, 2017.

16. Zhu J, Zeng Y, Xu C, Qin H, Lei Z, Shen D, Liu Z and Huang JA: Expression profile analysis of microRNAs and downregulated miR-486-5p and miR-30a-5p in non-small cell lung cancer. Oncol Rep 34: 1779-1786, 2015.

17. Liu Z, Zhang J, Gao J and Li Y: MicroRNA-4728 mediated regulation of MAPK oncogenic signaling in papillary thyroid carcinoma. Saudi J Biol Sci 25: 986-990, 2018. 
18. Li H, Zhou X, Zhu J, Cheng W, Zhu W, Shu Y and Liu P MiR-4728-3p could act as a marker of HER2 status. Cancer Biomark 15: 807-814, 2015.

19. Osmani L, Askin F, Gabrielson E and Li QK: Current WHO guidelines and the critical role of immunohistochemical markers in the subclassification of non-small cell lung carcinoma (NSCLC): Moving from targeted therapy to immunotherapy. Semin Cancer Biol 52: 103-109, 2018.

20. Livak KJ and Schmittgen TD: Analysis of relative gene expression data using real-time quantitative PCR and the 2(-Delta Delta C(T)) method. Methods 25: 402-408, 2001.

21. Singletary SE, Allred C, Ashley P, Bassett LW, Berry D, Bland KI, Borgen PI, Clark GM, Edge SB, Hayes DF, et al: Staging system for breast cancer: Revisions for the 6th edition of the AJCC cancer staging manual. Surg Clin North Am 83: 803-819, 2003.

22. Herbst RS, Morgensztern D and Boshoff C: The biology and management of non-small cell lung cancer. Nature 553: 446-454, 2018.

23. Hall RD, Gray JE and Chiappori AA: Beyond the standard of care: A review of novel immunotherapy trials for the treatment of lung cancer. Cancer Control 20: 22-31, 2013.

24. Walters S, Maringe C, Coleman MP, Peake MD, Butler J, Young N, Bergstrom S, Hanna L, Jakobsen E, Kölbeck K, et al: Lung cancer survival and stage at diagnosis in Australia, Canada Denmark, Norway, Sweden and the UK: A population-based study, 2004-2007. Thorax 68: 551-564, 2013.

25. Chen W, Zheng R, Baade PD, Zhang S, Zeng H, Bray F, Jemal A, Yu XQ and He J: Cancer statistics in China, 2015. CA Cancer J Clin 66: 115-132, 2016.

26. Wei F, Wang M, Li Z, Wang Y and Zhou Y: MiR593 inhibits proliferation and invasion and promotes apoptosis in non-small cell lung cancer cells by targeting SLUG-associated signaling pathways. Mol Med Rep 20: 5172-5182, 2019.
27. Yang D, Li JS, Xu QY, Xia T and Xia JH: Inhibitory Effect of MiR-449b on cancer cell growth and invasion through LGR4 in non-small-cell lung carcinoma. Curr Med Sci 38: 582-589, 2018.

28. Tang X, Ding Y, Wang X, Zhao L and Bi H: MiR-650 promotes non-small cell lung cancer cell proliferation and invasion by targeting ING4 through Wnt-1/ $\beta$-catenin pathway. Oncol Lett 18 : 4621-4628, 2019.

29. He S, Liao B, Deng Y, Su C, Tuo J, Liu J, Yao S and Xu L: MiR-216b inhibits cell proliferation by targeting FOXM1 in cervical cancer cells and is associated with better prognosis. BMC Cancer 17: 673, 2017.

30. Bi CW, Zhang GY, Bai Y, Zhao B and Yang H: Increased expression of miR-153 predicts poor prognosis for patients with prostate cancer. Medicine (Baltimore) 98: e16705, 2019.

31. Schmitt DC, Madeira da Silva L, Zhang W, Liu Z, Arora R, Lim S, Schuler AM, McClellan S, Andrews JF, Kahn AG, et al: ErbB2-intronic microRNA-4728: A novel tumor suppressor and antagonist of oncogenic MAPK signaling. Cell Death Dis 6: e1742, 2015.

32. Newie I, Sokilde R, Persson H, Grabau D, Rego N, Kvist A, von Stedingk K, Axelson H, Borg A, Vallon-Christersson J and Rovira C: The HER2-encoded miR-4728-3p regulates ESR1 through a non-canonical internal seed interaction. PLoS One 9: e97200, 2014

This work is licensed under a Creative Commons Attribution-NonCommercial-NoDerivatives 4.0 International (CC BY-NC-ND 4.0) License. 